\title{
Intraplant Sampling of Grapevines for Pierce's Disease Diagnosis
}

Rayda K. Krell, Thomas M. Perring, Charles A. Farrar, and Yong-Lak Park, Department of Entomology, University of California, Riverside 92521; and Carmen Gispert, University of California Cooperative Extension, Indio 92201

\begin{abstract}
Krell, R. K., Perring, T. M., Farrar, C. A., Park, Y.-L., and Gispert, C. 2006. Intraplant sampling of grapevines for Pierce's disease diagnosis. Plant Dis. 90:351-357.

The bacterium Xylella fastidiosa Wells et al. induces Pierce's disease (PD) of grapevine. This study was initiated to improve sampling protocols to identify $X$. fastidiosa-infected grapevines (Vitis vinifera L.) in California vineyards. Several potential PD symptoms, including leaf necrosis and chlorosis, internodal distance, petiole length and weight, and extent of cane branching, were not reliable indicators of $X$. fastidiosa infection. The matchstick symptom (i.e., abscised leaf blades leaving behind a dried, burnt-appearing petiole tip) was the only consistent indicator of infection in X. fastidiosa-positive grapevines. Further study revealed that leaves selected from the most basal nodes of positive canes had the highest probability of X. fastidiosa detection, with enzyme-linked immunosorbent assay. A symptom reliability index (SRI) was created to assess visual PD diagnosis by node location. The SRI values were the highest at basal node locations, but symptoms at any single node were not consistently reliable for PD diagnosis. Our results showed that PD diagnosis based on foliar symptoms was unreliable. However, taking samples from the basal portion of a cane increased the probability of $X$. fastidiosa detection.
\end{abstract}

Additional keywords: epidemiology, management

Pierce's disease (PD) of grapevine, induced by a xylem-inhabiting bacterium, Xylella fastidiosa Wells et al. (4), can result in plant death within 2 years after inoculation (5). PD was described in California in the 1880s (20) during an epidemic in Orange County, and a second epidemic occurred in Tulare County in the 1930s (10). After these epidemics, PD was considered an occasional problem confined to northern California until the late 1990s (12). In 1997, PD was identified in Temecula, an area of southern California where the disease previously was not considered a problem $(2,3)$. By 2002, approximately $40 \%$ of vineyard hectares were removed in the Temecula area because of PD (B. Mulherin, Office of the Riverside County Agricultural Commissioner, personal communication). In this epidemic area, the glassy-winged sharpshooter (Homalodisca coagulata Say) was the most frequently caught insect vector known to transmit $X$. fastidiosa (2). The glassy-winged sharpshooter is native to the southeastern United States (30) and first was documented in California in 1990 (25). The presence of this exotic vector raised new

Corresponding author: Thomas M. Perring

E-mail: thomas.perring@ucr.edu

Accepted for publication 25 October 2005.

DOI: 10.1094/PD-90-0351

(C) 2006 The American Phytopathological Society concerns about the rate and geographic range of $X$. fastidiosa spread.

One component of recent PD research in California has been the development of sampling programs to monitor $X$. fastidiosa incidence in grapevines. Monitoring vineyards for $X$. fastidiosa is important for three reasons. First, it is unclear how PD might progress in the presence of the recently introduced glassy-winged sharpshooter, and accurate measures of X. fastidiosa incidence are critical for understanding epidemiology. Second, the identification of $X$. fastidiosa is an important part of the current management strategies being used to limit its spread. University of California guidelines for PD management state that "chronically infected vines should be removed as soon as they are detected." (29). This reduces the possibility of secondary spread and increases vineyard productivity by replanting with healthy grapevines. Third, monitoring $X$. fastidiosa incidence is important for evaluating the efficacy of areawide programs to reduce vectors and subsequent disease.

Landscape-scale PD monitoring programs in Kern County (1,460 ha; 9) and the Coachella Valley $(4,600$ ha; 18,19$)$ in California have relied on the preliminary diagnosis of PD with visual symptoms. Disease symptoms, such as leaf marginal necrosis $(11,28)$, chlorosis (8), matchsticks (i.e., abscised leaf blades leaving behind a dried, burnt-appearing petiole tip; 27), and uneven cane maturation (13) are caused when bacteria colonize and block xylem vessels (26). However, PD symptoms can be similar to other grape diseases and physiological conditions $(7,29)$, and diseased grapevines are asymptomatic early in disease progression (11). PD diagnosis based on visual symptoms has been particularly ineffective in the desert environment of the Coachella Valley. From 2001 to 2004 , we conducted valleywide PD surveys and collected leaves for $X$. fastidiosa diagnostic analyses based on PD visual symptoms (i.e., leaf marginal necrosis). In these studies, our visual assessment was correct, as determined by enzymelinked immunosorbent assay (ELISA), for only $0.0,1.1,1.0$, and $2.7 \%$ of the samples in 2001, 2002, 2003, and 2004, respectively (17). In sampling studies in Kern County, the percentage of positive PD diagnosis based on visual symptoms, and confirmed by ELISA, ranged from 0 to $100 \%$ (mean $=25 \%$; J. Hashim, personal communication), indicating that the use of symptoms to diagnose PD is unreliable.

Identification of PD based on visual symptoms can result in two types of error, designating a grapevine as infected when it is healthy (i.e., Type I error) and designating a grapevine as healthy when it is infected (i.e., Type II error). Both types of error can lead to incorrect management decisions, such as removing healthy vines or leaving sources of inoculum in the field. The unreliable nature of visual symptoms as indicators of PD is such that incidence must be confirmed by diagnostic methods such as culturing, ELISA, or polymerase chain reaction (PCR). At present, no study has determined the optimal location on a grapevine from which plant tissue should be taken for the tests. Any technique for diagnosing PD could be erroneous if optimal plant tissue is not selected for testing. In a preliminary study, we found that individual petioles from the same grapevine cane could be $X$. fastidiosa positive or negative by ELISA, depending on where the petiole was located on the cane (unpublished data). Sampling protocols to detect infected grapevines in vineyards are needed to diagnose PD reliably.

The present study had three objectives: (i) describe the relationship between PD foliar symptoms and $X$. fastidiosa detection, (ii) compare the morphology of $X$. fastidiosa-positive and -negative grapevine canes, and (iii) determine the optimal location on canes from which to take leaf petiole samples for $X$. fastidiosa testing. In addressing these objectives, our goal was 
to establish protocols that researchers and growers can use for choosing grapevine foliage to identify $X$. fastidiosa-infected grapevines.

\section{MATERIALS AND METHODS}

Sample collection and bacterial detection. Grapevines (Vitis vinifera L.) naturally infected with $X$. fastidiosa were identified by ELISA in four California vineyards in Bakersfield (Kern County), Mecca, Temecula, and Thermal (Riverside County) (Table 1). All grapevines were sampled shortly after grapes were harvested. In 2003, grapevines were sampled in July and August in Mecca and July, August, and September in Thermal. In 2004, grapevines were sampled in September and October in Temecula and October in Bakersfield. At each vineyard, canes from $X$. fastidiosa-positive grapevines were removed and transported to the laboratory. It is likely that all X. fastidiosapositive grapevines had systemic infections because multiple canes were infected (26). Canes were stored at $4^{\circ} \mathrm{C}$ for 3 days or less before processing. In addition to the $X$. fastidiosa-positive canes collected, three canes from two $X$. fastidiosa-negative grapevines were collected at each vineyard in Mecca and Thermal. All canes from Mecca and Thermal were examined by measuring the length of each petiole, internodal distance, and the number of leaves branching from each node. On canes from all vineyards, every primary leaf from each cane was removed and photographed with a digital camera (MVC-CD300; Sony Inc., Tokyo) under the same laboratory illumination. Each leaf location was recorded by node number and each petiole was weighed.

ELISA was used for all diagnostic tests because it is a relatively low-cost method for evaluating a large number of samples, such as those taken for landscape-scale surveys. For all $X$. fastidiosa-positive and -negative canes, every primary petiole was tested separately. Whole petioles were subjected to ELISA according to the kit manufacturer's instructions (Agdia Inc., Elkhart, IN), with the following modifications. Petioles were macerated in sample extraction pouches (Agdia Inc.) with 1.5 $\mathrm{ml}$ of general extraction buffer (Agdia Inc.). After addition of the peroxidase sub- strate (o-phenylenediamine dihydrochloride), microtiter plates were incubated for approximately $30 \mathrm{~min}$ and read at $492 \mathrm{~nm}$ on a plate reader (Model 2550 EIA Reader; Bio-Rad, Richmond, CA). Samples were considered $X$. fastidiosa positive if the absorbance value was greater than the mean of two negative control samples (i.e., petioles from an $X$. fastidiosa-negative grapevine) plus three standard deviations (13).

Relationship between PD foliar symptoms and $X$. fastidiosa detection. To evaluate objectively the effectiveness of using foliar symptoms to diagnose PD, we measured green leaf area as an indication of symptom severity. The amount of green leaf area and total area of each leaf were measured by counting pixels in digital photographs of each leaf with Photoshop Pro (version 7; Adobe Systems Inc., San Jose, CA) by using the histogram function. Green was defined as red-green-blue values ranging from approximately 32-78-0 (dark green) to 195-216-46 (light green). To determine total leaf area when portions of the leaf were missing, the leaf outline was approximated by using leaf symmetry and connecting missing leaf portions. Because PD foliar symptoms can be difficult to distinguish from other environmental causes and can vary depending on cultivar, the percentage green leaf area was used as an indication of the amount of asymptomatic leaf area. PD foliar symptoms were interpreted with a range from $0 \%$ green leaf area (most symptomatic) to $100 \%$ green leaf area (asymptomatic). In an additional analysis of symptoms, the occurrence of the matchstick symptom was documented and the frequency of $X$. fastidiosa-positive petioles exhibiting the symptom was calculated. Matchsticks are petioles with abscised leaf blades leaving behind a dried, burnt-appearing petiole tip (27). To analyze the reliability of foliar symptoms for diagnosing PD, the percentage correct diagnosis based on four levels of symptoms $(<100,<75,<50$, and $<25 \%$ green leaf area) was calculated.

Morphological comparison between $X$. fastidiosa-positive and -negative canes. For samples from Mecca and Thermal, the differences in petiole weight, petiole length, internodal distance, and number of leaves occurring at a node were compared between $X$. fastidiosa-positive and -negative grapevine canes by analysis of variance (ANOVA) and multivariate analysis of variance (MANOVA) (PROC GLM; 23).

Location of $X$. fastidiosa-positive and -negative petioles on canes. Because canes had different numbers of nodes (Table 1), node location was standardized. Each node was numbered sequentially, with 1 being the most basal node. Each node number was divided by the total number of nodes occurring on the cane and rounded to the nearest tenth. All nodes were categorized into a relative node location from 0.0 to 1.0 , with 0.0 or 0.1 being the most basal node depending on the total number of nodes. To examine how the relative location of petioles on a cane (basal to distal) was related to PD symptoms and $X$. fastidiosa detection, the mean proportion of $X$. fastidiosa-positive petioles was examined by node location. To estimate the relationship between the probability of $X$. fastidiosa detection and node location of a petiole, regression analyses were used to fit these data (PROC NLIN; 23). The best regression models were chosen based on $R^{2}$ values, and $95 \%$ confidence intervals for the means were calculated.

We analyzed the reliability of symptoms for PD diagnosis by node location. If foliar symptoms are a reliable indicator of $X$. fastidiosa infection, then the percentage green area of negative leaves should be high and the percentage green area of positive leaves should be low. To determine if PD symptoms and $X$. fastidiosa detection were related by node location, a symptom reliability index (SRI) was created. The index was calculated as $\left(G_{\mathrm{N}}-G_{\mathrm{P}}\right) / 100$ for each node, where $G_{\mathrm{N}}$ is the mean percentage green area of the negative leaves and $G_{\mathrm{P}}$ is the mean percentage green area of the positive leaves. The index was divided by 100 to obtain an SRI value ranging from -1.0 to1.0, where -1.0 indicates the least reliability of symptoms and 1.0 indicates the best reliability of symptoms for diagnosing PD.

\section{RESULTS}

Relationship between PD symptoms and $X$. fastidiosa detection. Among all vineyards, when symptomatic leaves were

Table 1. Cane sample description from Xylella fastidiosa-positive grapevines

\begin{tabular}{|c|c|c|c|c|c|}
\hline Vineyard & Cultivar ${ }^{\mathbf{a}}$ & Year vineyard planted & Total grapevines & Total canes $^{\text {b }}$ & $\begin{array}{c}\text { Mean number of nodes per cane } \\
( \pm \text { standard error })\end{array}$ \\
\hline Bakersfield & Thompson Seedless & 1981 & 6 & $17^{\mathrm{c}}$ & $37.24 \pm 3.23$ \\
\hline Mecca & Perlette & 1970 & 3 & $12^{\mathrm{d}}$ & $19.17 \pm 2.08$ \\
\hline Temecula & Sauvignon Blanc & 1974 & 5 & $13^{\mathrm{e}}$ & $22.77 \pm 0.33$ \\
\hline Thermal & Superior Seedless & 1987 & 6 & 18 & $25.78 \pm 1.62$ \\
\hline
\end{tabular}

a All cultivars were planted on their own rootstock.

b Three canes were collected from each grapevine unless otherwise indicated.

c Only two canes were collected from one grapevine of the six.

${ }^{\mathrm{d}}$ Four and five canes were collected from two grapevines of the three.

e Only two canes were collected from two grapevines of the five. 
broadly defined as $<100 \%$ green leaf area, Type II error was low and symptoms could be used to diagnose infection correctly in 92 to $100 \%$ of the petioles (Bakersfield, $n=$ 386; Mecca, $n=102$; Temecula, $n=97$; and Thermal, $n=303$; Fig. 1). Interestingly, these percentages represented 4,8 , and $20 \mathrm{X}$. fastidiosa-positive petioles with $100 \%$ green leaf area from Mecca, Temecula, and Thermal, respectively. However, under this same definition, Type I error was high and only 0 to $23 \%$ of the negative petioles from positive canes were diagnosed correctly (Bakersfield, $n=41$; Mecca, $n=14$; Temecula, $n=116$; and Thermal, $n=78$ ). As the definition of symptoms was more narrowly defined from $<100$ to $<25 \%$ green leaf area, Type II error increased because fewer X. fastidiosa-positive petioles were diagnosed correctly, and Type I error decreased because more $X$. fastidiosa-negative petioles were diagnosed correctly at all vineyards. At $<25 \%$ green leaf area, 70 to $97 \%$ of the negative samples were correctly diagnosed and only 5 to $69 \%$ of the positive petioles were correctly diagnosed. In Temecula, most $X$. fastidiosa-positive samples had a high percentage of green leaf area, so that diagnosis of positive samples was low at all levels except $<100 \%$ green. The trend for diagnosing negative samples was similar for petioles from the X. fastidiosa- negative grapevines from Mecca $(n=120)$ and Thermal $(n=163)$, with diagnosis being more accurate as the definition of symptomatic leaves was narrowed from $<100$ to $<25 \%$ green leaf area (Fig. 2).

Although the usefulness of the percentage green leaf area for diagnosing PD was variable, the matchstick symptom was a consistent indicator of $X$. fastidiosa infection in the positive canes. In 211 occurrences of matchstick symptoms from $X$. fastidiosa-positive canes from all vineyards, $100 \%$ were positive. The only exception to the reliability of the matchstick symptom was a single matchstick petiole from one $X$. fastidiosa-negative cane from Mecca.

Morphological comparison between $X$. fastidiosa-positive and -negative canes. There were no significant differences $(P>0.05)$ between $X$. fastidiosapositive and -negative canes based on measurements of petiole weight, petiole length, internodal distance, and number of leaves branching from a node when considered as separate factors (ANOVA), or combined (MANOVA) (Table 2). Because no differences were found, these cane attributes were not measured on the samples collected in 2004.

Location of $X$. fastidiosa-positive petioles on canes. At all vineyards, petioles taken from the most basal node location had the highest probability of $X$. fastidiosa detection (Fig. 3) at the lower $95 \%$ confidence interval. The lowest probability of $X$. fastidiosa detection occurred at Temecula, where, at the most basal node location, there was only a $43 \%$ chance of identifying infection at the lower $95 \%$ confidence interval. The highest probability of detection was at Thermal, where the most basal node location had a $94 \%$ chance of positive $X$. fastidiosa detection with $95 \%$ confidence. At Bakersfield and Mecca, there was a 69 and $88 \%$ chance, respectively of positive $X$. fastidiosa detection in the most basal node locations at the lower 95\% confidence intervals.

At Bakersfield and Mecca, the variability in $X$. fastidiosa detection increased at more distal node locations, as evidenced by the widening confidence intervals at more distal node locations. This result reinforces the potential advantage of using basal leaves for $X$. fastidiosa diagnostic tests because of the lower variability in the sample results. Interestingly, at Bakersfield, the regression line representing the mean probabilities of $X$. fastidiosa detection actually increased at more distal cane petioles; however, because of the increasing variability in the data, the confidence interval decreased. Overall, at Bakersfield, the means reflected the high degree of severity of $X$. fastidiosa infection; how-
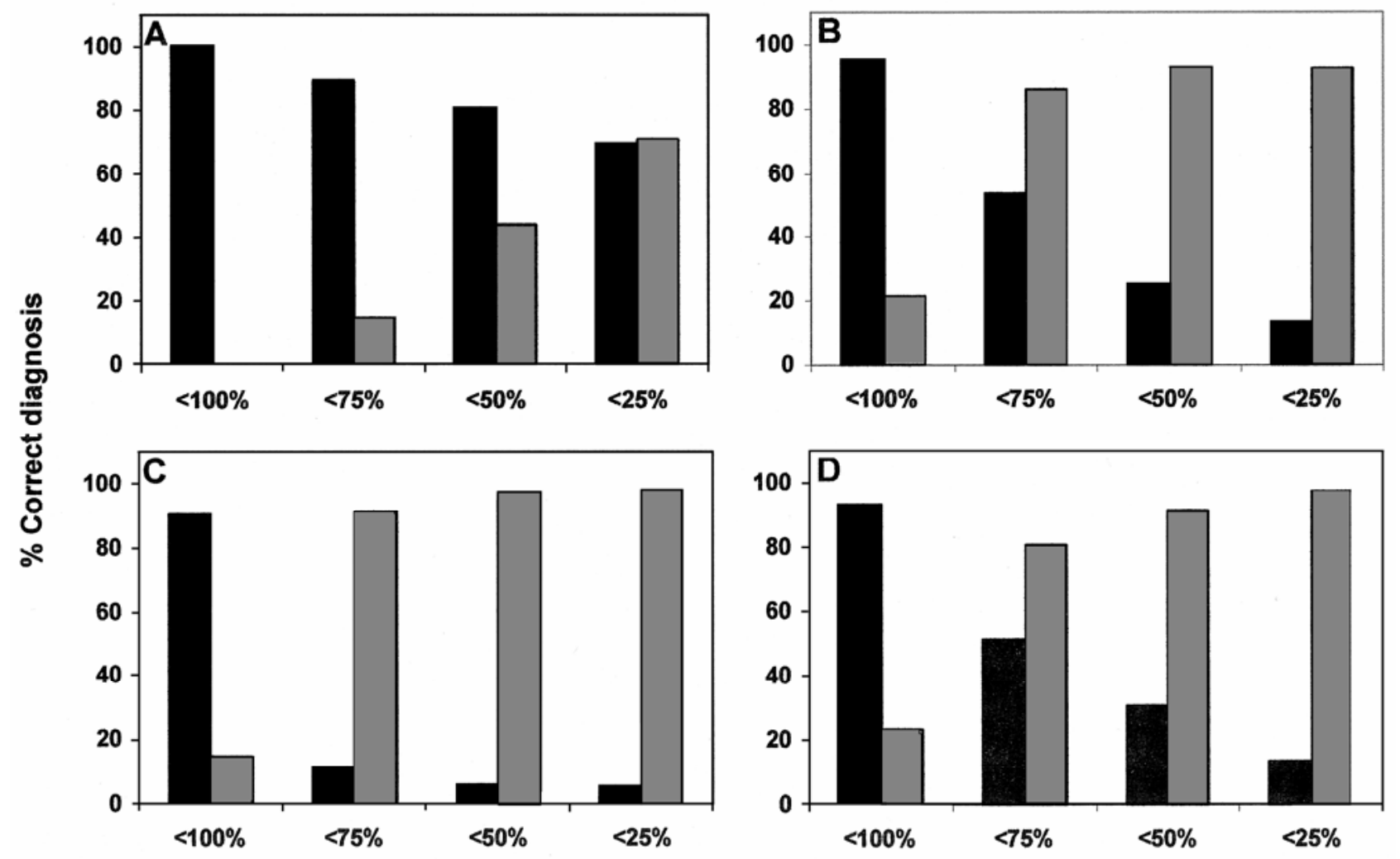

$\%$ Green leaf area defining positive PD diagnosis

Fig. 1. Percentage of Xylella fastidiosa-positive (black bars) and -negative (gray bars) petioles correctly diagnosed from X. fastidiosa-positive canes based on four levels of green leaf area for visual diagnosis of a positive or negative leaf. Correct diagnosis of Pierce's disease (PD) was confirmed by testing each petiole with enzyme-linked immunosorbent assay. A, Bakersfield, B, Mecca, C, Temecula, and D, Thermal. 
ever, even given this severity, the most reliable location to sample was at the base of canes.

Although the probability of $X$. fastidiosa detection decreased distally along canes, the same trend was not true for symptom reliability for PD diagnosis (Fig. 4). Among SRI values, the highest index value (0.52) was found at node 0.5 in Bakersfield (Fig. 4). At each vineyard, index values were highest at node location 0.6 or less and all values were $>0$ at node location 0.2 or less, but no individual node from all vineyards was a consistent indicator at which symptoms could be used to reliably diagnose an $X$. fastidiosa-positive or -negative grapevine.

\section{DISCUSSION}

In our study, the proportion of Type I to Type II error in PD diagnosis based on visual foliar symptoms changed depending on how symptoms were defined. We found that a broad definition of symptomatic leaves $(<100 \%$ green leaf area) could be used to detect most of the infected petioles; however, this level resulted in 67 to 100\% Type I error at all four field sites. Alternatively, a more narrow definition of symptomatic $(<25 \%$ green leaf area) was a reliable way to identify the negative petioles but resulted in 31 to $91 \%$ Type II error at all sites. Overall, no single definition of foliar symptoms provided an accurate diagnosis of PD.

Other studies on PD have documented various frequencies of Type I error. Krivanek et al. (13) found that leaves from water-inoculated grapevines had a relatively high percentage $(18.9 \%)$ of scorched area. Also, in their study, leaf scorching was as high as $57 \%$ in grape cultivars considered resistant to PD. Milholland et al. (15) used microscopy to observe that, in leaves with severe marginal leaf burn, only $1.6 \%$ of the vessels actually contained bacteria.

Documenting Type II error in PD diagnosis is somewhat more difficult, because detecting $X$. fastidiosa in grapevines does not necessarily mean the plant will develop PD. Several studies have documented asymptomatic grapevine tissue colonized by $X$. fastidiosa. Newman et al. (16) showed that asymptomatic leaves can be colonized by $X$. fastidiosa, but symptoms are more likely to occur when vessels are completely blocked by bacteria. Goodwin et al. (8) found up to $50 \%$ of asymptomatic leaves were actually $X$. fastidiosa positive (8), and Hopkins (11) found up to $52 \% X$. fastidiosa-infested vessels in petioles from leaves with no symptoms. Schaad et al. (24) found that $26 \%$ of asymptomatic vines were $X$. fastidiosa positive. In our study, asymptomatic leaves were $X$. fastidiosa positive in 5 to $8 \%$ of the petioles from three locations.

It is possible that error in PD diagnosis could be reduced with the use of sensitive diagnostic techniques such as PCR or bacterial culturing. In our study, we chose to use ELISA because the high cost of PCR limits its utility for large-scale PD surveys covering thousands of hectares, and there is evidence that the two methods are comparable. Bextine and Miller (1) compared PCR and ELISA for $X$. fastidiosa detection in samples from symptomatic grapevines and found no significant differences in detection. Also, they found 38\% symptomatic $X$. fastidiosa-negative samples and $21 \%$ asymptomatic $X$. fastidiosa-positive samples by whole-tissue ELISA, compared with $38 \%$ symptomatic $X$. fastidiosanegative samples and $23 \%$ asymptomatic $X$. fastidiosa-positive samples by wholetissue PCR, indicating a similar occurrence of both types of error by two diagnostic methods. Additionally, the use of a more sensitive technique might detect more $X$. fastidiosa-positive samples; however, because the detection thresholds of the technique are lower, these plants might not actually develop PD.

Under current PD sampling protocols, which are based on sampling symptomatic leaves, Type I error generally is tolerable because all leaves are tested with ELISA or PCR to confirm $X$. fastidiosa infection. However, sampling costs increase as the frequency of Type I error increases because more symptomatic $X$. fastidiosanegative leaves are tested. In contrast, Type II error is not tolerable because asymptomatic $X$. fastidiosa-positive leaves are not sampled and tested. Thus, sampling protocols to decrease the error, especially Type II error, are needed to improve PD diagnosis and management. The timing of sampling also will affect the proportion of Type I to Type II error. If grapevines are sampled early in the season before symptoms have had time to develop, there is the potential for more Type II error. If grapevines are sampled late in the season there is the potential for more Type I error because natural senescence could be confused with PD symptoms. In our study, sampling was performed after grapes were harvested at each location. The solution to managing both types of error will be to develop systematic sampling programs that do not rely on visual symptoms for sampling.

Our results, combined with those from previous studies, build a strong case that

Table 2. Test statistics for analysis of variance (ANOVA) and multivariate analysis of variance (MANOVA) with the hypothesis of $H_{0}$ : there is no morphological difference in cane structure between Xylella fastidiosa-negative and -positive canes ${ }^{\mathrm{a}}$

\begin{tabular}{lcc}
\hline Statistical tests & Mecca & Thermal \\
\hline ANOVA $(F \text { values })^{\mathrm{b}}$ & & \\
Petiole weight & 0.84 & 0.93 \\
Petiole length & 0.98 & 0.77 \\
Internodal distance & 0.71 & 0.71 \\
No. leaves at branch & 0.70 & 0.69 \\
MANOVA & \\
$\Lambda^{\mathrm{c}}$ & 0.57 & 0.89 \\
$F$ & 0.69 & 0.51 \\
\hline a All tests were not significant at $P=0.05$. \\
b df $=1,14$ at Mecca and df $=1,20$ at Thermal. \\
c Wilks' lambda with df $=4,11$ at Mecca and df \\
$\quad=4,17$ at Thermal.
\end{tabular}

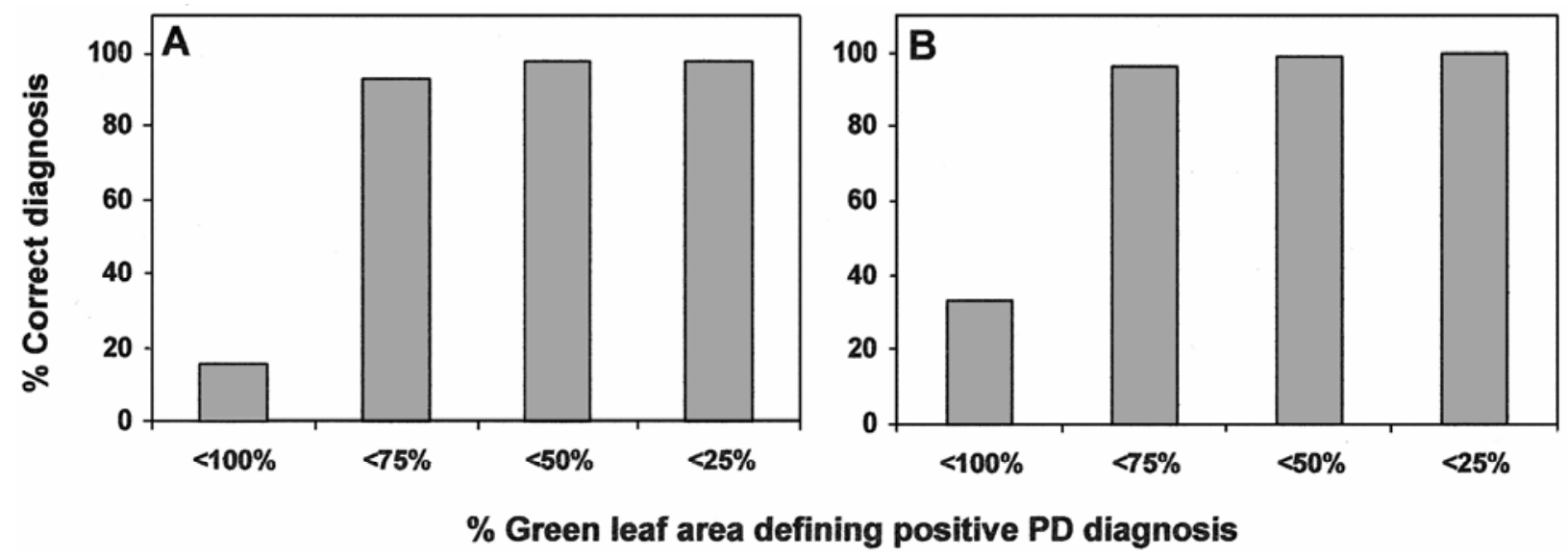

Fig. 2. Percentage of Xylella fastidiosa-negative petioles from X. fastidiosa-negative canes correctly diagnosed based on four levels of green leaf area for visual diagnosis of a positive or negative leaf. Correct diagnosis of Pierce's disease (PD) was confirmed by testing each sample with enzyme-linked immunosorbent assay. A, Mecca and B, Thermal. 
foliar symptoms are not reliable for diagnosing PD. It is possible that other nonfoliar PD symptoms may be more reliable for disease diagnosis. Krivanek et al. (13) found a good relationship between uneven cane maturation, often referred to as the green island symptom, and $X$. fastidiosa infection; however, this relationship has been shown only in a greenhouse environment.

Matchsticks were the best symptom to consider for visual PD diagnosis. Petioles were classified as matchsticks only if the leaf blade was abscised and the petiole tip was dry and darkened. All matchsticks from infected canes were X. fastidiosa positive; however, not all infected canes had matchsticks and one healthy cane had a $X$. fastidiosa-negative matchstick. Most matchsticks (187 of 211 matchsticks from all vineyards) were observed from the Bakersfield vineyard, where infection in these grapevines was the most severe. No matchsticks were found in grapevines from the Temecula vineyard, although there were green petioles with abscised leaf blades at this location. It is possible that no matchsticks were identified from Temecula because the cv. Sauvignon Blanc might not express this symptom, matchsticks might have abscised before we sampled, or the infection might have not progressed enough to induce matchsticks. In Coachella Valley surveys (17), the matchstick symptom was included as a symptom to diagnose PD in 1 year (i.e., 2004) of a 4year survey, and more $X$. fastidiosapositive grapevines were identified that year compared with other years of the survey.

For field sampling to diagnose PD, it is important to determine when the matchstick symptom is most reliable. This study was done in all vineyards shortly after harvest and, generally, matchsticks were not common in fields. Later in the season, petioles with abscised leaf blades become more common as plants senesced, even though many of these petioles did not have a darkened tip. Also, it is possible the matchstick symptom may have been present only in severely infected vines, and would not be present in grapevines with new infections. Although Rost et al. (22) report that the matchstick symptom appeared "after several days of $X$. fastidiosa infection" in young grapevines under a greenhouse condition, mature grapevines under natural field conditions may respond differently to inoculation.

There were no morphological differences detected between healthy and in- fected canes. It is possible that the cane attributes that we measured are not good indicators of grapevine health in the cultivars we examined. Goodwin et al. (8) took measurements from 10 infected and 10 healthy Chardonnay vines and found fewer canes per vine, shorter canes, and reduced leaf area in infected grapevines. Also, it is possible the vines in their study were more severely infected, resulting in significant differences.

As an alternative to choosing plant tissue for diagnostic tests based on symptoms, we examined whether some petiole locations on a cane might have a greater probability of positive $X$. fastidiosa detection. The probability of detecting a positive was greatest for samples from the base of canes. Our findings are supported by a recent study examining greenhouse-grown $V$. vinifera showing that the $X$. fastidiosa populations in petioles were either lowest at the location most distal to the point of inoculation (cv. Chenin Blanc) or approximately uniform (cv. Chardonnay) at all node locations distal to the point of inoculation (14). In our study, the lowest probability of detection occurred at the Temecula vineyard, where many basal leaves were missing. The cultivar we examined at the Temecula vineyard, Sauvi-
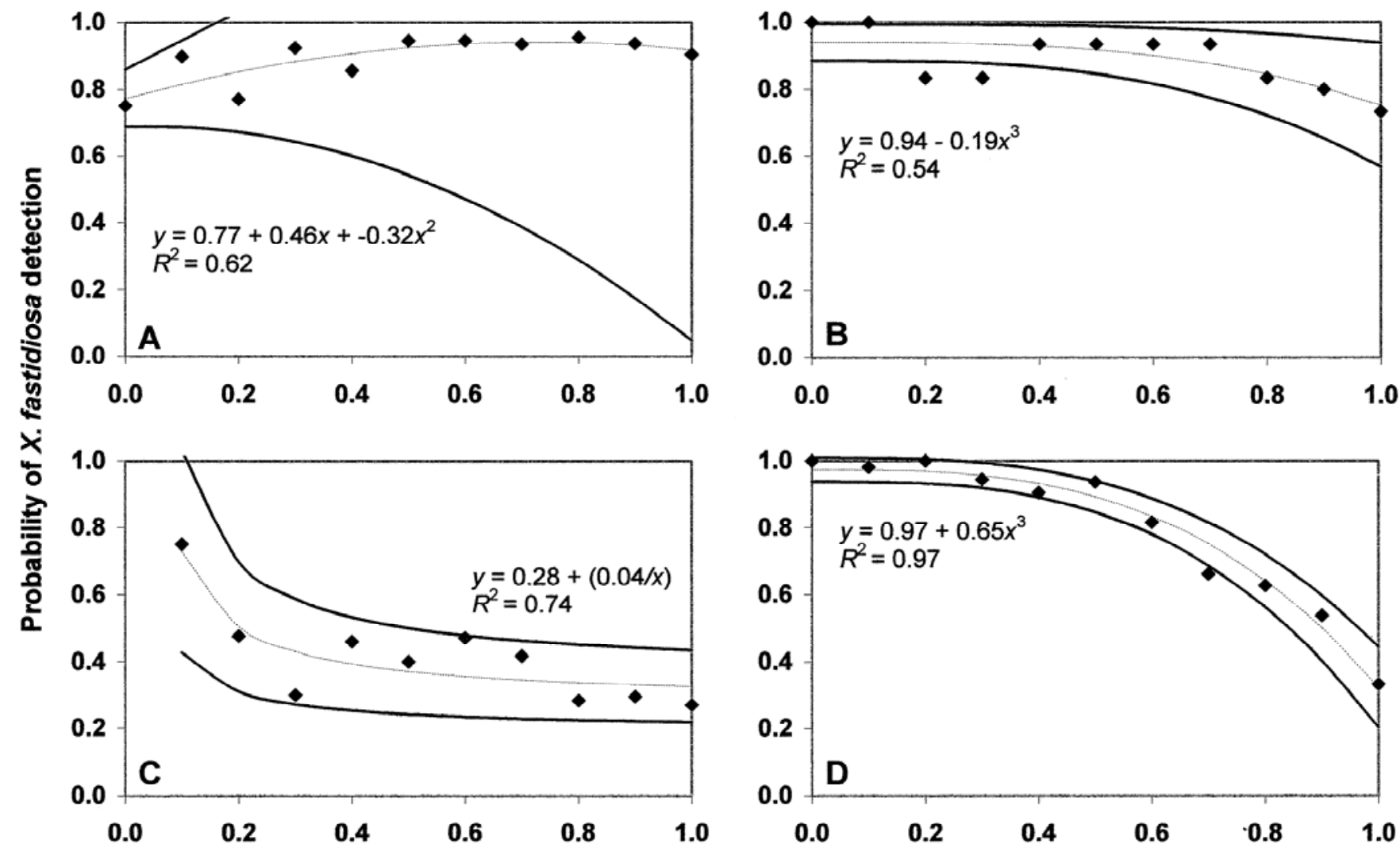

\section{Relative node location}

Fig. 3. Probability of Xylella fastidiosa detection from X. fastidiosa-positive canes at A, Bakersfield, B, Mecca, C, Temecula, and D, Thermal. Diamonds show the mean probability of positives at each node, the dotted line represents best fit of the data, and the solid lines represent upper and lower $95 \%$ confidence intervals for the mean. 
gnon Blanc, is known to be one of the most susceptible grape cultivars (21), and basal leaves may have abscised very early in the season, before we collected samples. The probability of detecting positive petioles at the base of canes may have been higher in Temecula if there had been more basal petioles to analyze. Based on our results, the best protocol to reduce error in field PD sampling is to remove a few basal petioles from grapevines and pool the petioles for diagnostic tests. An advantage to diagnosing PD based on a sample from a basal cane petiole is that the infection is more likely to be the result of a chronic infection. Because basal infections are likely to be chronic, the possibility of removing a grapevine that may recover from PD because the infection is pruned out (5) or does not survive cold temperatures (6) is lessened.

Although basal petiole samples had the highest probability of $X$. fastidiosa detec- tion, there was not a trend of decreasing symptom reliability distally along canes. Other studies have reported indices to measure PD symptoms $(13,15)$, but this study is the first to create an index that reflects the reliability of using PD symptoms to diagnose $X$. fastidiosa infection.

This study documents problems related to using visual foliar symptoms to diagnose PD infection and identifies a reliable method for choosing plant tissue for $X$. fastidiosa diagnostic tests. We found that, in four vineyards representing different cultivars and grown in varying environments, sampling basal petioles from canes was the best method for accurately identifying $X$. fastidiosa-positive grapevines, regardless of foliar symptoms. We used a readily available $X$. fastidiosa test kit that commonly is used to diagnose PD for management purposes. The next step to improve PD sampling will be to develop comprehensive programs for monitoring
PD in vineyards. Our results will be a useful component of modified PD sampling protocols and will minimize both types of error and reduce sampling costs.

\section{ACKNOWLEDGMENTS}

We thank the California Desert Grape Administrative Committee and the University of California Pierce's Disease program for financial support, J. Hashim for assisting with identification of infected grapevines in Bakersfield, CA, the growers who allowed us to work in their vineyards, and J. Nay for helpful comments on this manuscript.

\section{LITERATURE CITED}

1. Bextine, B. R., and Miller, T. A. 2004. Comparison of whole-tissue and xylem fluid collection techniques to detect Xylella fastidiosa in grapevine and oleander. Plant Dis. 88:600-604.

2. Blua, M. J., and Morgan, D. J. W. 2003. Dispersion of Homalodisca coagulata (Hemiptera: Cicadellidae), a vector of Xylella fastidiosa, into vineyards in Southern California. J. Econ. Entomol. 96:1369-1374.

3. Blua, M. J., Phillips, P. A., and Redak, R. A. 1999. A new sharpshooter threatens both crops and ornamentals. Calif. Agric. 53:22-27.
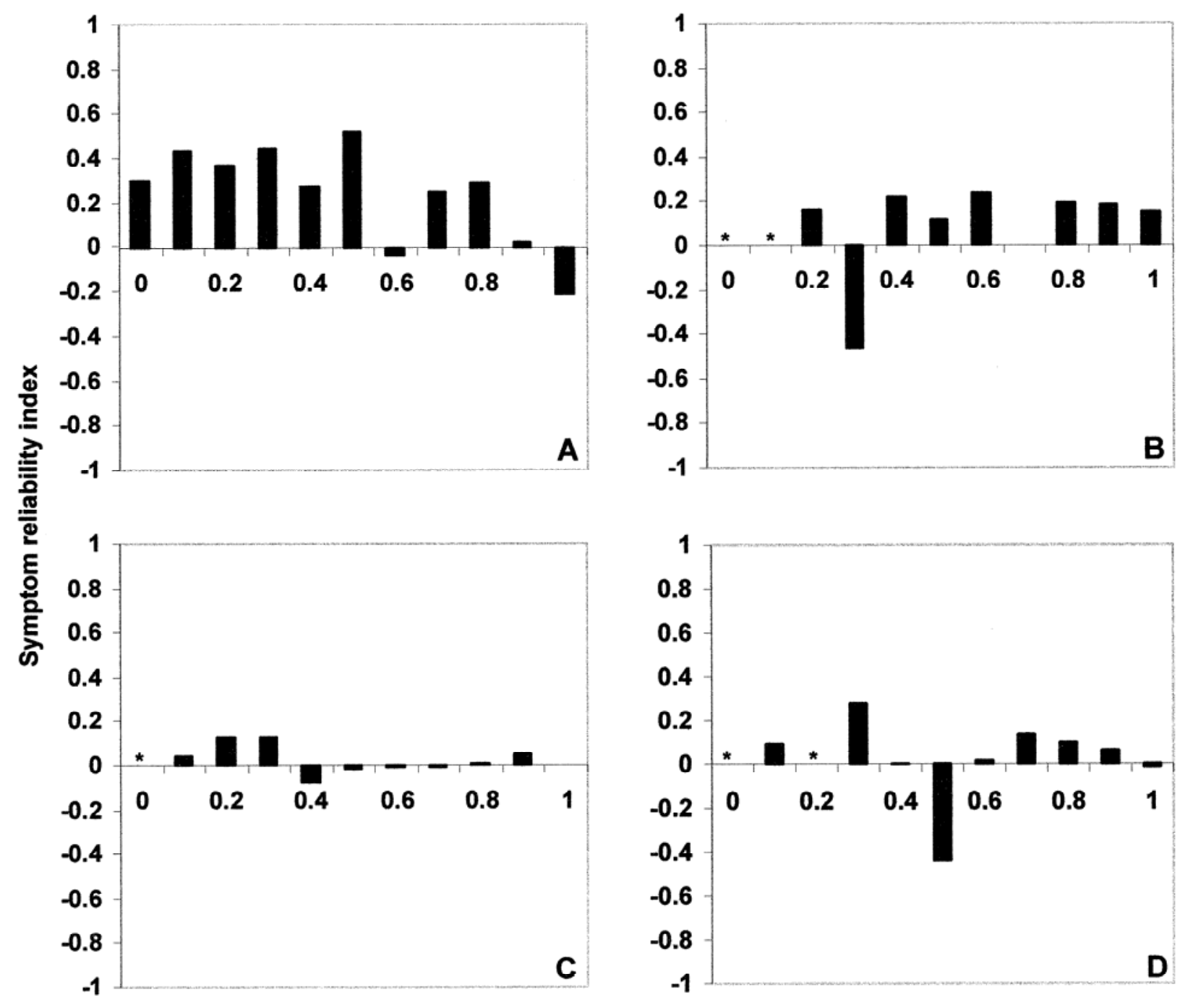

Relative node location

Fig. 4. Symptom reliability index (SRI) by node at A, Bakersfield, B, Mecca, C, Temecula, and D, Thermal. The SRI was calculated by subtracting the mean percent green area of the positive leaves from the mean percent green area of the negative leaves and dividing by 100 to obtain a value ranging from -1.0 to 1.0, where -1.0 indicates the least reliability of symptoms and 1.0 indicates the best reliability of symptoms for diagnosing Pierce's disease. An asterisk indicates that the value could not be calculated because no $X$. fastidiosa-negative petioles occurred at the node location. 
4. Davis, M. J., Purcell, A. H., and Thompson, S. V. 1978. Pierce's disease of grapevines: isolation of the causal bacterium. Science 199:7577.

5. Feil, H., Feil, W. S., and Purcell, A. H. 2003. Effects of date of inoculation on the withinplant movement of Xylella fastidiosa and persistence of Pierce's disease within field grapevines. Phytopathology 93:244-251.

6. Feil, H., and Purcell, A. H. 2001. Temperaturedependent growth and survival of Xylella fastidiosa in vitro and in potted grapevines. Plant Dis. 85:1230-1234

7. Flaherty, D. L., Christensen, L. P., Lanini, W. T. , Marois, J. J., Phillips, P. A., and Wilson, L. T., eds. 1992. Grape Pest Management, 2nd ed. University of California, Division of Agriculture and Natural Resources, Oakland.

8. Goodwin, P. H., DeVay, J. E., and Meredith, C. P. 1988. Physiological responses of Vitis vinifera cv. Chardonnay to infection by the Pierce's disease bacterium. Physiol. Mol. Plant Pathol. 32:17-32.

9. Hashim, J., Hill, B. L., Kelly, M., Shari, D., and Purcell, A. H. 2003. Monitoring and control measures for Pierce's disease in Kern County and epidemiological assessments of Pierce's disease. Pages 95-98 in: Proc. Pierce's Disease Res. Symp. Coronado, CA. M. A. Tariq, S. Oswalt, P. Blincoe, R. Spencer, L. Houser, A. Ba, and T. Esser, eds. California Department of Food and Agriculture, Sacramento.

10. Hewitt, W. B., Frazier, N. W., Freitag, J. H., and Winkler, A. J. 1949. Pierce's disease investigations. Hilgardia 19:207-264.

11. Hopkins, D. L. 1981. Seasonal concentration of the Pierce's disease bacterium in grapevine stems, petioles, and leaf veins. Phytopathology 71:415-418.

12. Hopkins, D. L., and Purcell, A. H. 2002. Xylella fastidiosa: Cause of Pierce's disease of grapevine and other emergent diseases. Plant Dis. 86:1056-1066.

13. Krivanek, A. F., Stevenson, J. F., and Walker,
M. A. 2005. Development and comparison of symptom indices for quantifying grapevine resistance to Pierce's disease. Phytopathology 95:36-43.

14. Krivanek, A. F., and Walker, M. A. 2005. Vitis resistance to Pierce's disease is characterized by differential Xylella fastidiosa populations in stems and leaves. Phytopathology 95:44-52.

15. Milholland, R. D., Huang, P. Y., Clayton, C. N., and Jones, R. K. 1981. Pierce's disease on muscadine grapes in North Carolina. Plant Dis. 65:73-74.

16. Newman, K. L., Almeida, R. P. P., Purcell, A H., and Lindow, S. E. 2003. Use of a green fluorescent strain for analysis of Xylella fastidiosa colonization of Vitis vinifera. Appl. Environ. Microbiol. 69:7319-7327.

17. Park, Y. L., Perring, T. M., Krell, R. K., Farrar, C. A., and Gispert, C. Spatial distribution of Pierce's disease in the Coachella Valley: implications for sampling. Am. J. Enol. Vitic. In press.

18. Perring, T. M., Gispert, C., Farrar, C. A., and Krell, R. 2003. Epidemiology of Pierce's disease in the Coachella Valley. Pages 107-110 in: Proc. Pierce's Disease Res. Symp. Coronado, CA. M. A. Tariq, S. Oswalt, P. Blincoe, R. Spencer, L. Houser, A. Ba, and T. Esser, eds. California Department of Food and Agriculture, Sacramento.

19. Perring, T. M., Gispert, C., Farrar, C. A., Krell, R. K., and Y. L. Park. 2004. Area-wide epidemiology of Pierce's disease in the Coachella Valley. Pages 43-46 in: Proc. Pierce's Disease Res. Symp. Coronado, CA. M. A. Tariq, S. Oswalt, P. Blincoe, A. Ba, T. Lorick, and T. Esser, eds. California Department of Food and Agriculture, Sacramento.

20. Pierce, N. B. 1882 . The California vine disease. U. S. Div. Veg. Physiol. Pathol. Bull. No. 2.

21. Raju, B. C., and Goheen, A. C. 1981. Relative sensitivity of selected grapevine cultivars to Pierce's disease bacterial inoculations. Am. J.
Enol. Vitic. 32:155-158

22. Rost, T. L., Matthews, M. A., and Stevenson, J. 2004. Mechanisms of Pierce's disease transmission in grapevines: the xylem pathways and movement of Xylella fastidiosa, progress report number two: green islands and matchsticks. Pages 50-53 in: Proc. Pierce's Dis. Res. Symp. Coronado, CA. M. A. Tariq, S. Oswalt, P. Blincoe, A. Ba, T. Lorick, and T. Esser, eds. California Department of Food and Agriculture, Sacramento.

23. SAS Institute. 1999. SAS OnlineDoc, Version 8, SAS Institute Inc., Cary, NC.

24. Schaad, N. W., Opgenorth, D., and Gausch, P. 2002. Real-time polymerase chain reaction for one-hour on-site diagnosis of Pierce's disease of grape in early season asymptomatic vines. Phytopathology 92:721-728.

25. Sorensen, J. T., and Gill, R. J. 1996. A range extension of Homalodisca coagulata (Say) Hemiptera: Cylpeorrhyncha: Cicadellidae) to Southern California. Pan-Pac. Entomol. 72:160-161.

26. Stevenson, J. F., Matthews, M. A., Greve, L. C., Labavich, J. M., and Rost, T. L. 2004. Grapevine susceptibility to Pierce's disease II progression of anatomical symptoms. Am. J. Enol. Vitic. 55:238-245.

27. Stevenson, J. F., Matthews, M. A., and Rost, T. L. 2005. The developmental anatomy of Pierce's disease symptoms in grapevines: green islands and matchsticks. Plant Dis. 543 548.

28. Tyson, G. E., Stojanovic, B. J., Kuklinski, R. F., DiVittorio, T. J., and Sullivan, M. L. 1985. Scanning electron microscopy of Pierce's disease bacterium in petiolar xylem of grape leaves. Phytopathology 75:264-269.

29. Varela, L. G., Smith, R. J., and Phillips, P. A 2001. Pierce's Disease. Univ. Calif. Agric. Nat. Resour. Publ. No. 21600.

30. Young, D. A, Jr. 1958. A synopsis of the species of Homalodisca in the United States (Homoptera: Cicadellidae). Bull. Brooklyn Entomol. Soc. 53:7-13 